\title{
Global bioethics and human rights in an African context: A reformed theological discourse on global bioethics as a new human rights ethos
}

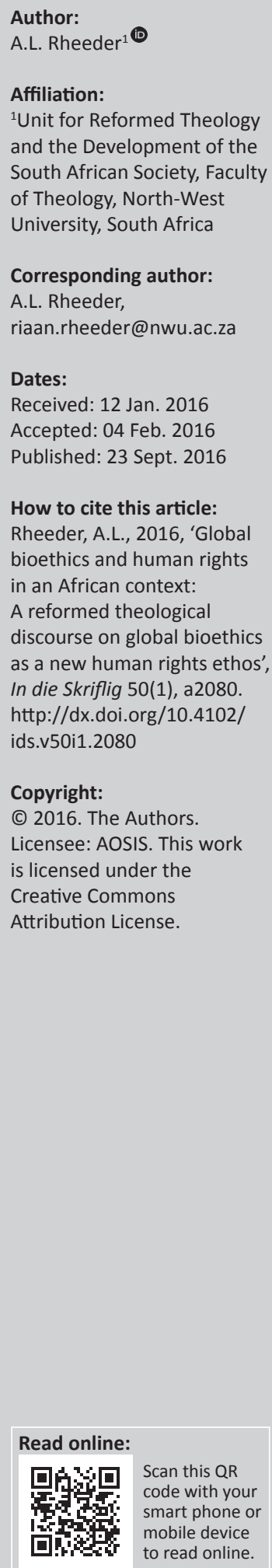

\begin{abstract}
The 2005 UNESCO Universal Declaration of Bioethics and Human Rights (UDBHR) is specifically aimed at Africa and developing countries from other regions. The acceptance of this UNESCO instrument shows that global bioethics and human rights have become part of the bioethics discourse of today. It is clear that there is a certain affinity between human rights and bioethics, which makes such a link desirable. The value of this link lies in the fact that human rights facilitate a normative universal expansion of bioethical principles. The human rights framework provides bioethical principles with some authority and political influence, an instrument that can protect people in our broken context. Human rights practice and a reformed understanding of natural law both show that humanity can reach consensus on ethical principles such as those found in the UDBHR. Consensus on the theoretical foundation of human rights is not a prerequisite for the successful utilisation of these principles.
\end{abstract}

\section{Problem statement}

Bioethics is increasingly characterised by a global discourse (Iltis 2011:145) and a link with human rights. After the Second World War various intergovernmental and international organisations have come into being, like the European Council, UNESCO, WHO, the Council for International Organizations of Medical Sciences and the World Medical Association (WMA), all of which established ethical guidelines related to bioethics. Examples are the Declaration of Helsinki 1964 (current edition: WMA 2013), the Proposed International Guidelines for Biomedical Research Involving Human Subjects 1982 (current edition: Council for International Organizations of Medical Sciences 2002), the Declaration on the Human Genome and Human Rights (UNESCO 1997) and the Convention on Human Rights and Biomedicine (Council of Europe Convention on Human Rights and Biomedicine 1997) (Faunce 2014:472; Ten Have \& Gordijn 2014:832). These instruments interlink in varying degrees with human rights, but they have all contributed to the development of a global bioethics.

The Universal Declaration on Bioethics and Human Rights of UNESCO (2006; hereafter UDBHR) is the most recent example of a link between human rights and specifically global bioethics (Iltis 2011:145) and will be the focus of this contribution. Ten Have and Gordijn (2014), supported by Semplici (2015:57) explain the importance of this instrument as follows:

The Universal Declaration on Bioethics and Human Rights is the first global instrument that endeavors to cover the entire field of bioethics. (p. 832)

It can therefore be regarded as epitomising global bioethics' recourse to the human rights tradition.

The research question discussed in this article is whether such a link as established by the UNESCO instrument is desirable. Are there good arguments in favour of presenting global bioethical norms within a human rights framework? This problem is set against the background of certain objections against such a link in the bioethics community. Two arguments in particular dominate the criticism. It is argued in the first place that there is no global consensus on the foundation of human rights. In addition the idea of universality is questioned. The question is whether it would not rather be wise to discard the human rights approach in the light of this criticism and to 'be satisfied with registering the plurality of philosophies, and harmonizing them as much as possible' (Semplici 2015:58).

In an effort to answer the research question the article first pays attention to the nature of the UDBHR as a global bioethics, namely its universality, its expression of the link between global bioethics and human rights and its global (African) context. Secondly, arguments in favour of the link between a global bioethics and human rights are investigated. In the third place objections to 
the link between a global bioethics and human rights are considered. Finally, in the fourth place a suggestion for a theoretical foundation for a global bioethics is made from a reformed perspective.

The central theoretical statement of the article is that powerful instruments support the linkage between global bioethics and human rights as expressed in the UNESCO document. These instruments are non-religious in nature and they do not have a theoretical foundation; therefore they are said to be universal. It is proposed in this article that a reformed understanding of natural law could offer a foundation for human rights. Although the primary addressees of this article are from the reformed tradition, it is further proposed that a reformed understanding of natural law could enable all people, both religious and secular, to share certain values whether or not they are able to reach consensus about a religious justification for human rights.

The scope of this article does not allow a discussion of the historical differences in understanding natural law in the reformed tradition (or in other traditions). I will therefore focus on the latest research and point of view of the Reformed ethicist J.M. Vorster (2015:37-59) on natural law as discoursed in his recent book on ethics, secularism and human rights. In some circles the theological foundation of human rights from a reformed perspective is questioned, as it would violate the universal validity of human rights. If such a view would be accepted, one could ask whether a secular foundation of human rights would not likewise violate the universal validity and acceptability of human rights.

According to the International Bioethics Committee of UNESCO (IBC) (2004:2-4) and Ten Have and Jean (2009:31) representatives of Islam, Confucianism, Buddhism, Hinduism, Christianity (Roman Catholicism) and Jewish traditions all had the opportunity to state their views during the development of the UDBHR (IBC 2004:2-4; Ten Have \& Jean 2009:31). However, Tham (2014:2) indicates that over the course of a long development process and much debate only one opportunity was offered to religions to make a contribution. What is more, he adds that there was no contribution from the Protestant tradition.

The Christian grounding of universal bioethical (and human rights) principles is a new development in Protestant theology and has been introduced by Macaleer (2014), who clearly shows that no Protestant ethicist has as yet given indepth attention to a theoretical framework for modern global bioethical principles. His book (or thesis), The New Testament and bioethics: Theology and basic bioethics principles, deals with the theoretical grounding of four universal bioethical principles as formulated by Beauchamp and Childress, namely autonomy, beneficence, maleficence and justice. Macaleer (2014) summarises these principles as follows:

As outlined by Beauchamp and Childress, these principles are based on what they call the common morality. Thus, the principles have no specific theological foundation; this book attempts to give those principles a Scriptural foundation. (pp. ix-x)
In an African (South African) context the purpose and necessity of such a study is clearly understood. The UDBHR was accepted unanimously by the global community (191 member countries) in 2005 (IBC 2008:45), which means that the declaration is the first and to date the only political bioethical text to which all the member governments of the United Nations, including South Africa, have committed themselves (UNESCO 2005). In spite of this commitment, Langlois (2013), who studied the reception of the UDBHR in South Africa and Kenia, notes the following:

The Universal Declaration helps put bioethics on the agenda of States ... It appears to have had little or no impact in South Africa, however, on what is a growing and developing bioethics community. (p. 154)

This article aims to contribute to an awareness of the UDBHR in the (South) African context from the perspective of theological science. Berlinguer (2009:304, 307) refers to Article 23 of the UDBHR which declares that governments should promote education in (universal) bioethics and that all institutions should make a contribution to education, which, according to Berlinguer, should be interdisciplinary as well. Mathooko and Kipkemboi (2014), two UDBHR researchers from Africa, are of the opinion that bioethics education in Africa is sorely needed:

The relevance of bioethics education in Africa is not in doubt ... Despite the efforts by UNESCO to promote bioethics education in Africa, it is still in its infancy and its development is bedevilled by numerous challenges ... (pp. 259-260)

With reference to the above-mentioned need, one can mention that unlike all the other bioethical instruments, the UDBHR is particularly directed at developing countries.

This article focuses on global bioethics and human rights as formulated in the UDBHR. The aim is to determine the UNESCO perspective on the research question, and therefore the literature on the subject is primarily selected from literature by UNESCO itself. It includes reports on activities as described by Ten Have and Gordijn (2014:841): ' ... UNESCO is already constructively involved in a range of international activities focused on bioethics curriculum development, designing teaching materials and the training of bioethics teachers'.

In the light of the above discussion the subsequent section pays attention to the existence of a global bioethics as embodied in UNESCO literature.

\section{The UDBHR as a global bioethics}

In the light of the existing UNESCO teaching material, this subsection firstly concentrates on the universal nature of the UNESCO declaration, secondly on the link between bioethics and human rights and thirdly on the global (African) context that necessitates a global bioethics.

1 According to UNESCO (2006, Art 2[f]): The aims of this Declaration are to promote (a) equitable access to medical, scientific and technological developments as well a the greatest possible flow and the rapid sharing of knowledge concerning those developments and the sharing of benefits, with particular attention to the needs of developing countries... 


\section{The universal nature of the declaration}

UNESCO is a speciality organisation within the United Nations (UN) which was established in 1945. The organisation's point of departure is that peace between nations should be built on intellectual (scientific) and moral solidarity. UNESCO has been busy with bioethics since 1970 (in the form of conferences and symposiums) and established the IBC in 1993. They expressed their concern about the relationship between science and morality as early as 1987 (UNESCO 1987:109). The $\mathrm{UN}$ is the only platform with a mandate in both science and ethics where all the nations of the world (and not only certain regions or cultures) have the opportunity to develop, discuss and negotiate values and principles that they may potentially share in an effort to ultimately agree on normative instruments (Ten Have 2013a:11).

In 2003 the member countries of UNESCO gave the organisation the mandate to develop a universal declaration on bioethics. In 2005 the Universal Declaration on Bioethics and Human Rights (UNESCO 2006) was accepted with acclamation. This declaration states 15 bioethical principles as a global bioethics. Article 2(a) describes the purpose of the principles as follows:

The aims of this Declaration are ... to provide a universal framework of principles and procedures to guide States in the formulation of their legislation, policies or other instruments in the field of bioethics.

This instrument offers bioethical principles as a 'universal framework'. What does UNESCO mean by the concept of universal? Firstly, it means global or worldwide. Three strategies were followed during the creation of this declaration to reach worldwide consensus. One was that the declaration built on previous instruments on which there had been consensus, such as the Universal Declaration of Human Rights (UN 1949) and the Convention on Human Rights and Biomedicine (Council of Europe Convention on Human Rights and Biomedicine 1997). The second strategy was to use consensus within UNESCO and to expand it to the area of bioethics by considering the principles of the Universal Declaration on the Human Genome and Human Rights (UNESCO 1997) and the International Declaration on Human Genetic Data (UNESCO 2003). In the last instance consultation was as global and diverse as possible. Experts, organisations and institutions from different member countries were consulted. Conferences were hosted in The Netherlands, Iran, Lithuania, Turkey, Argentina, South Korea, Mexico, Indonesia, Portugal and Russia to consult with experts. Material for discussion by any person was placed on UNESCO's website. Speakers from different religious and spiritual traditions participated in this discussion (Ten Have 2013a:13).

The result of this strategy is that the UDBHR is currently the only bioethical instrument in the form of principles and human rights that has been accepted by all the member countries (governments of 193 countries) of the UN and of which all signatories have agreed to apply the principles. The UDBHR has a global aim. It is not aimed at only one specific world region, like for instance the Oviedo Convention on Biomedicine of the European Union (Council of Europe Convention on Human Rights and Biomedicine 1997) and is presented as a bioethical instrument that is not the asset of only one specific culture, area or country, but the property of the world community. The declaration states specific ethical principles that underlie the concept of global ethical responsibility, which means that countries are not only responsible for respecting and protecting its own citizens, but they also have a broader worldwide (global) ethical task. Article 15 of the UDBHR (2006) expresses the specific principle that denotes a global moral community:

Benefits resulting from any scientific research and its applications should be shared with society as a whole and within the international community, in particular with developing countries.

The emphasis is on sharing the benefits, in particular with the developing world.

Secondly, universal is understood as uniting and allencompassing. The scope of the declaration denotes that the guidelines are meant for' '... individuals, groups, communities, institutions and corporations, public and private' (UDBHR 2006). This declaration did not come into existence exclusively in the medical profession and its addressees are not only the medical community, as in the case of the Declaration of Helsinki (WMA 2013); it comprises more than only medical or nursing ethics. In addition the UNESCO declaration deals with the entirety of bioethical themes when compared to the Universal Declaration on the Human Genome and Human Rights (UNESCO 1997), which is only aimed at genetics (Ten Have \& Gordijn 2014:832-833). The emphasis is not only on ethical principles that affect the individual, but also on the social principles that affect the community. The ethical principles are not only aimed at the current generation, but are also meant for future generations (UDBHR 2006:Art. 16). There are also ethical principles intended for the ecology and the environment (2006:Art. 17). The human community is extended to land, water, plants and animals (Ten Have 2013a:4-6).

Thirdly, universal also indicates a global common property and identity. The concept of the common heritage of humankind became part of international law during the late sixties with the aim of regulating common resources like the ocean floor and outer space. In the seventies it was extended to include cultural heritage. The concept common property expresses the fact that certain resources or cultural goods do not belong to one country specifically and do not represent only one culture, but that they are the property of humanity. UNESCO, for instance put De Pont du Gard in France on the world heritage list together with approximately 900 monuments from across the world. These monuments, as expressions of cultural heritage, are masterpieces that serve as examples of human creativity. Every monument is the property of the country in which it is situated, but is also regarded and conserved as the common property of humanity (Ten Have 2011:110-111). In the Universal Declaration on the 
Human Genome and Human Rights (UNESCO 1997) the human genome is also seen as a common heritage of the global community. Ten Have (2013a) has the following view of culture:

... cultural heritage is no longer only representative of a particular culture but of human culture in general ... Such heritage is the expression of human identity at a global level; they are part of the quest of the citizens of the world; they become indicators of world culture. (p. 8)

\section{The link between bioethics and human rights}

One of the special elements in the UDBHR is the close link between bioethics and human rights. Ten Have and Gordijn (2014) describe the relationship as follows:

As a result, it has a principal orientation on human rights discourse. After all, the Universal Declaration involves an expansion of international human rights law into the arena of medicine, life sciences, and healthcare. (p. 830)

The chairperson of the group responsible for the formulation of a concept declaration regards the integration of bioethical principles within a human rights framework as the most important achievement of the declaration (Kirby 2006:126).

In what way does the UDBHR link bioethics and human rights? According to Ten Have (2013a:165) the relationship between human rights and bioethics in the UDBHR is heterogeneous, complex and of three kinds. Human rights firstly form the point of departure and context of bioethics (Ten Have \& Gordijn 2014:833). The bioethical principles offered in the declaration are interlocked with human rights as reflected in the title of the instrument, namely Universal Declaration on Bioethics and Human Rights. The preamble to the declaration refers to human rights as the context in which bioethical principles have developed and in which ethical problems should be analysed (UDBHR 2006):

Recognizing that ethical issues ... should be examined with due respect to the dignity of the human person and universal respect for, and observance of, human rights and fundamental freedoms.

The context of international human rights is further emphasised in one of the explicit aims of the declaration. Article 2(c) (UDBHR 2006) states this aim as follows:

to promote respect for human dignity and protect human rights, by ensuring respect for the life of human beings, and fundamental freedoms, consistent with international human rights law.

Secondly, human rights form the basis of bioethical principles (Ten Have \& Gordijn 2014:833). Although the UDBHR does not offer the bioethical principles in a hierarchy, it is noteworthy that the first of the 15 bioethical principles links human rights to human dignity. It could be concluded that it views human rights as the foundation of bioethical principles; it could also be said that human rights give meaning to the concept of human dignity (Andorno 2009). Article 3 (Human dignity and human rights) reads as follows:

Human dignity, human rights and fundamental freedoms are to be fully respected. The interests and welfare of the individual should have priority over the sole interest of science or society. (p. 95)

In the third place Ten Have and Gordijn (2014:833) are of the opinion that human rights serve as limitations and the final authority on bioethical principles. It is confirmed in different places that bioethical principles should be regarded, interpreted and applied as international human rights (and not as optional ethical principles). The preamble to the declaration explains the limitations as follows: 'Recognizing that this Declaration is to be understood in a manner consistent with domestic and international law in conformity with human rights law ...' (UDBHR 2006).

Several articles in the declaration confirm that bioethical principles should be understood and applied in conjunction with human rights. The bioethical principle of informed consent (Art. 6) states that an exception is only possible when it is in line with international human rights legislation. The bioethical principles of substitute consent (Art. 7), privacy and confidentiality (Art. 9) and discrimination and stigmatisation (Art. 11) confirm this conformity to human rights (UDBHR 2006).

Additionally the UNESCO declaration formulates two relatively new bioethical principles that support the link with human rights. The first is expressed in Article 12 which states that cultural diversity and pluralism in ethical decisionmaking may be taken into consideration, but 'such considerations are not to be invoked to infringe upon ... human rights ...' (UDBHR 2006). Due to this limitation this article can be viewed as the weakest in the declaration. The second principle is found in Article 14(2) which deals with social responsibility and health and clearly states: 'Taking into account that the enjoyment of the highest attainable standard of health is one of the fundamental rights of every human being ...' (2006). Articles 27 and 28 of the UDBHR contain conditions for the limitation and interpretation of the principles. Article 27 indicates that the limitation of an ethical principle may only be considered in very specific circumstances where legislation, which should agree with human rights, provides for public safety, for investigating, determining and prosecuting criminal offences, and for protecting public health, or where the rights and freedoms of other should be protected. Article 28 states the following:

Nothing in this Declaration may be interpreted as implying for any State, group or person any claim to engage in any activity or to perform any act contrary to human rights, fundamental freedoms and human dignity.

\section{The global (African) context}

The global context that resulted in the global bioethical discourse and the link with human rights are discussed in short in this section. It is important to indicate that global bioethics should be understood in the context of globalisation. The incentive to create a universal bioethical and human rights instrument has not developed in a vacuum. The world today is characterised by 'planetary compression' (global 
communication, movement and economic network) and 'psychic interpenetration' (greater mutual connection and a growing feeling of universal solidarity) as part of a process of unification (Ten Have 2013b:604-607). The increase in scientific articles in the area of global bioethics from 1971 (1) to 2010 (55) indicates that globalisation will not stop soon (Ten Have \& Gordijn 2014:829). There are several reasons why and practical examples of how bioethics has become part of the global discourse and has weighed more than the framework of human rights. One can for instance refer to the globalisation of the organ trade, (unequal) health care practices, scientific and technological developments, pandemics, climate change, obesity, malnutrition and inadequate food production.

The discussion focuses on only one example from the African context (where the researcher lives). Research in the development of new medication has become a large international endeavour from about 1990 onwards. Ten Have (2011:146-165) cites a telling example (see also Stanton-Jean, Doucet \& Le Roux 2014:743). In 1996 a meningitis epidemic erupted in the village of Kano in the predominantly Muslim North of Nigeria. Thousands of children were in danger of dying or becoming disabled. A state hospital offered free medical assistance to affected children in cooperation with Doctors Without Borders. A few weeks after the eruption of the epidemic, a research team arrived from Pfizer, which is the largest pharmaceutical company in the world. As a 'humanitarian gesture', the company offered a new antibiotic for the treatment of the children. Pfizer treated about 200 children. However, it was not explained to the parents or the children that the drug (Trovan) was an experimental drug and that the treatment of the children formed part of an existing scientific research study. Some children received the experimental drug and others received the approved medication. After 2 weeks the research team concluded their study and they returned to the United States, although the epidemic was still in full swing. In 1996 Pfizer applied to the American FDA (Food and Drug Administration) to commercialise the drug. In 1998 the drug was approved only for use in adults in the US, while it was not approved for use in Europe at all. In the meantime information surfaced that the treatment could have serious side effects.

Later research highlights the following unethical actions in Kano:

- The drug had never been tested on children before the project in Kano.

- Early research on animals had indicated the possibility of liver damage.

- During the research study half of the children received only half of the normal dosage of the approved medication; the aim was of making the experimental drug look good.

- Parents were never informed of the fact that experimental drugs were used and that they could receive free treatment with safe and effective medication from Doctors Without Borders.
- Neither the consent of parents nor the assent of the children was ever sought.

- Eleven children died over the course of the research study.

- A local medical doctor who was supposed to lead the research, was only the leader in name.

- The letter of consent from the ethics committee of the local hospital was forged because no such committee existed.

Since this occurrence, clinical research has been exported to Eastern Europe, Africa, India and China with even more frequency. From 2002 onwards the number of new applications for research in America decreased by 5.5\% due to the strict regulation of drug trials, while it increased by 15\% elsewhere. From 2007 onwards more research has been done outside America than in the country. Forty per cent of clinical experiments are performed in developing countries.

There are several reasons why research is being done in the developing world, but one reason is the lack of bureaucratic and complicated ethical guidelines and legislation. The export of clinical research to countries that do not have a strong ethical infrastructure (limited or no regulation, few or no ethical committees or experts) has caused and will still cause many problems, as the above-mentioned example shows (Ten Have 2013b:605). In court cases after the experiment in Kano, Pfizer claimed that the ethical principle of informed consent had not been necessary because there was no international norm that required it. The company asserted the norm was a typically western norm and could not be enforced in non-western countries. It is clear that one way to address this matter is the acceptance of a global bioethical framework that requires all members of the international community to take responsibility for each other by accepting the same ethical guidelines for everyone. Ten Have (2011) confirms this point of view as follows (translated from the Dutch):

The Trovan case illustrates the necessity of establishing a good infrastructure in the area of bioethics, internationally and nationally. If rules are in place and if consensus exists about ethical principles, the rules should be applied everywhere, whether the research takes place in Kano or in Utrecht. (p. 164)

The discussion now turns to the relationship between global bioethics and human rights.

\section{Arguments in favour of the connection between bioethics and human rights}

In the light of the reality and necessity of a global bioethics, the paragraphs below pay attention to the arguments in favour of the link between global bioethics and human rights. There are many reasons why it is preferable to present bioethical principles in the human rights context. UNESCO literature indicates especially three arguments in favour of a relationship between bioethics and human rights: an affinity exists between bioethics and human rights; a powerful 
framework of human rights principles can be expanded by normative guidelines; and the familiarity, the good reputation and especially the authority of human rights are conducive to the application of bioethical norms.

\section{Affinity between bioethics and human rights}

A deep-lying affinity between bioethics and human rights exists (Faunce 2014:471). The first argument in favour of this statement is that there are close historical links between the development of bioethics and human rights. Both the Nuremberg Code (1947) which has bioethical implications and the Universal Declaration of Human Rights (1948) have their origins in the same historical events, namely the Second World War and Nazi concentration camps. The Nuremberg Code had a definite influence on the Universal Declaration of Human Rights (UDHR). The circumstances that gave rise to these documents required a transcultural and transnational framework of principles that could be used to derive normative guidelines. The human rights framework offered a globally acceptable frame of reference that transcended culture, nationality and religion. Human rights and bioethics share three common characteristics, namely they have the same origin (the atrocities of the Holocaust and the need to prevent such atrocities in future); the same aims (never again may the human being be used as a means to and end; and the same claim to universality (Ten Have 2013a:19).

The second argument is that both bioethics and human rights seem to share concern about welfare (health), because both focus on the improvement of basic conditions such as the availability and sufficiency of drinking water and food, adequate housing and access to elementary health care (UDBHR 1960:Art. 14; Art. 25). Bioethics and human rights are therefore important when considering health, including physical, psychic and social welfare. The promotion of human rights will contribute to the improvement of public health. In addition one should note the common interest of bioethics and human rights in the sense that both are involved in supervision of life sciences and medicines. Both aim to offer an answer to or protection against the same social and historical powers and events at a local and especially a global level.

The third argument is that more and more instruments have made a link between human rights and bioethics over the last number of decades (Ten Have \& Gordijn 2014:835).

\section{Normative expansion of framework of human rights principles}

Human rights offer a powerful framework of principles from which normative guidelines can be derived. The human rights discourse establishes and promotes principles and norms that are non-negotiable and can therefore not be compromised. It offers a normative counterbalance for the dangers of utilitarian arguments. An example is the commitment to the integrity of the human body, which implies that torture, cruel punishment and organ trade are always wrong (UDBHR 1960:Art. 5). One must be aware that good arguments are sometimes put forward to justify these practices. The assertion has been made that it might be necessary to torture someone to get the necessary information to save the lives of other people. In the same vein, forcing poor people to trade in organs has been defended on the grounds that persons that have been waiting for a kidney for years and are in the end phases of kidney failure could be saved from certain death by receiving a traded kidney. In the health environment utilitarian arguments have always been dominant because of the emphasis on the convincing results of medical intervention (saving lives, healing and preventing disease). Ten Have (2013a:20) writes in this regard: 'When the effects of medical intervention are the predominant moral consideration, medical practice itself becomes normative: what is medically feasible is ethically required'. This type of argument has led to a long list of scandals and malpractices in medical research. Over and against this, human rights form a deontological framework of principles and norms. Regardless of medical results, everyone all over the world should respect the framework; in this way it would offer special protection for the entire human race. A human rights framework as a supervisory mechanism emphasises that any medical intervention or research on people may only be considered if certain principles are adhered to, for example informed consent. The utilitarian approach may only be used within a deontological framework of specific principles. The human rights discourse helps bioethics to establish principles that triumph over other considerations.

Since human rights take universality as a point of departure, such a framework enables the expansion of normative bioethical principles. Because of the characteristic of universality, human rights offer the possibility of calling for minimum normative standards (Andorno 2009:96). Global bioethics needs certain transcultural principles that are universal despite differences in sociocultural, philosophical and religious traditions; human rights offer this possibility. The Office of the United Nations High Commissioner for Human Rights (1996-2016) defines human rights as follows:

Human rights are rights inherent to all human beings, whatever our nationality, place of residence, sex, national or ethnic origin, colour, religion, language, or any other status. We are all equally entitled to our human rights without discrimination. These rights are all interrelated, interdependent and indivisible.

When you have to determine whether an entity has human rights, the only valid criteria is that of humanity. All other considerations such as geographic location, ethnicity, gender, political views and other related matters become less important. In this sense human rights rise above cultural diversity and dare to actualise what is right for all people (Ten Have \& Gordijn 2014:835-836). Universality promotes the unity and equal treatment of all people. Human rights are the foundation of equal (universal) standards for all.

It has been argued that bioethical principles are of western origin and are therefore not valid for other cultures. An example is the claim that the principle of informed consent is difficult to apply in illiterate populations or where tradition 
dictates the community or family should give the consent. Another argument, for instance emphasises the reality that ethical and care standards in western hospitals cannot be used in developing countries. The problem with this kind of argument is medical and research practices are measured and justified by double standards. In developing countries lower standards are applied because they are more readily accepted. A human rights narrative can address and rectify this kind of problematic argument. Ten Have (2013a) - with the Trovan case as background - explains the value of human rights in this regard as follows:

Human rights discourse can redress such tendencies and arguments, emphasizing that ethical principles are universal (research that is not ethical in the US is also not ethical in Nigeria), and that the ends do not justify the means (improving health care for a population does not justify exploitation of some citizens, taking advantage of poverty, lack of development or social misery to advance knowledge). (p. 21)

In addition to these arguments a normative human rights framework for all people can contribute to the promotion and restoration of human dignity. Bioethical principles are now viewed as every person's right, which implies that a vulnerable poor person is not viewed as a repulsive burden for the community; for this reason such a person may not be stigmatised and victimised. Vulnerable people are not viewed as needy strugglers, but as citizens of the world. Human rights make people equal and more powerful. Ten Have (2013a) expresses a positive view of human rights:

The second advantage is that rights dignify rather than victimize. People are no longer regarded as needy victims, but as citizens of the world with the same claims and rights as everyone else. (p. 23)

Human rights (in the UDBHR) offer a flexibility that to a certain degree makes universality (universal principles) reconcilable with cultural diversity. In other words, although human rights principles are universal, local differences may be considered when rights or bioethical principles are interpreted and applied. The preamble to the UDBHR clearly states that cultural diversity '... as a source of exchange, innovation and creativity, is necessary to humankind and, in this sense, is the common heritage of humanity', but at the same time the preamble also states that cultural diversity may not be used 'at the expense of human rights and fundamental freedoms' (UDBHR 2006). This principle is set out in Article 12 of the UDBHR (2006):

The importance of cultural diversity and pluralism should be given due regard. However, such considerations are not to be invoked to infringe upon human dignity, human rights and fundamental freedoms, nor upon the principles set out in this Declaration, nor to limit their scope.

It is clear that cultural diversity is important when other principles are interpreted and implemented within a specific context. 'Nevertheless ... respect for cultural diversity and pluralism is the only principle in the Declaration that can never overrule any of the other principles', Ten Have and Gordijn (2014:836) say emphatically.

\section{Application: Familiarity, reputation and authority of human rights}

Most people are familiar with human rights. However, the same is not true of ethical theories such as utilitarianism, deontology and virtue ethics, which are more familiar to academics. The broader familiarity provides human rights with an immediate advantage in search of an instrument for the creation, analysis and especially the application of global ethical norms for medicine, healthcare and life sciences. In addition human rights in general have a good reputation. Human rights offer a respected modus through which global social criticism can be expressed. Human rights are accepted as important and almost obvious international normative standards. It is for this reason that the transgression of human rights is usually seen as a serious and urgent event requiring immediate intervention. In the light of the above-mentioned familiarity and the fact that human rights form part of the international human rights law, the authority of human rights is accepted in almost all countries by almost all people; therefore they offer an inevitable and powerful discourse that is widely accepted all over the world. Ten Have and Gordijn (2014) quote a relevant remark of R.E. Ashcroft:

... casting a debate into human rights terms allows a welltested and long-established common language, rhetoric and institutional practice to be applied in order to achieve consensus both on the nature of the problem and, ideally, on the form of possible solutions to it. (p. 835)

Because of their familiarity, good reputation and especially their authority, human rights can be used more persuasively to exert global influence on moral principles. 'It is convenient to have a bioethical analysis outlining the rights and wrongs, but what is the point if it does not make a difference for the people involved?', Ten Have (2013a:21-22) enquires in his most recent research. Human rights have shown that they can be implemented effectively in fighting violence and corrupt practices. Ten Have and Gordijn (2014:836), however, warns against politicisation of human rights saying, 'Human rights discourse can effectively transform moral bravery into political clout'. Instead, global bioethical principles, which are frequently understood as non-compulsory kindheartedness, should be translated into the language of human rights. Such a global principle is the right to health, which includes among other things the improvement of poverty and illiteracy (UDBHR 2006:Art. 14, 2[e]). This means that addressing poverty and illiteracy becomes more than just a moral ideal and that the application of such an ethical principle is grounded in institutions such as courts, tribunals and truth commissions (Faunce 2014:473). Human rights and the accompanying institutional follow-up mechanisms can currently be viewed as the strongest instrument available to global bioethics to bring about social change (Andorno 2009:96; Ten Have \& Gordijn 2014:843). In this regard one can refer to the Trovan case. Ten Have and Gordijn (2014) motivate using the Trovan case as an example as follows:

An example of the impact of the association of bioethics and human rights is the Trovan case in Nigeria. Following the unjustified experiment of Pfizer in the city of Kano, Nigerian 
families brought the pharmaceutical company to court in the USA. After an initial dismissal, the judiciary decided in 2009 that Pfizer should be condemned since informed consent is a universal ethical norm, so that not applying this norm is in fact a crime against humanity. (p. 837)

Global bioethics that is grounded in a human rights framework forms an excellent instrument that can be used by bioethics activists and pressure groups. In the current phase of globalisation, the global society rather than national states is eagerly promoting human rights. The same goes for global bioethics, which is also driven by a global movement comprising health workers, scientists and citizens and whose focus on the promotion of bioethical principles is much stronger than that of governments. For a global bioethics that is aimed at efficiently addressing important ethical problems, it makes sense to link up with the human rights movement, because human rights have substantial support within the networks of the global community and non-governmental organisations. There are NGOs consisting of medical personnel like the International Red Cross, Physicians for Human Rights and Médècins SansFrontières and those that include non-medical personnel like Amnesty International and Human Rights Watch. The global civil society monitors, prevents, relieves and describes several transgressions by states and other institutions. Faunce (2014) puts it thus:

Along with nonphysician groups such as Amnesty International and Human Rights Watch, many of their members view themselves as at the vanguard of a cosmopolitan world order normatively governed more by human rights than by bioethics. (p. 472)

Therefore bioethics can exert more and more efficient influence with the help of human rights (Ten Have \& Gordijn 2014:836). Against the background of the Trovan case, Ten Have (2013a) explains the value of human rights for activism as follows:

Now that all countries have adopted a basic universal framework of bioethical principles (the UNESCO Universal Declaration on Bioethics and Human Rights) and similar research and healthcare activities are undertaken in many parts of the world, it has become evident that bioethics infrastructures are very different and that bioethics principles are not equally applied. Advocacy can help in reinforcing these infrastructures and better implementing bioethical principles. (p. 25)

In modern times it is increasingly found that policies with a bioethical drift have to be formulated in many areas. Individuals and commissions are consulted and have to make recommendations with regard to policy. The formulation of international policy is becoming a reality. At a national level, several persons and committees act as advisors to civil officials that have to develop legislation. At a local level several people and committees advise for instance hospital councils and research institutions with regard to guidelines and policy. Bioethical guidelines in the form of human rights are especially suited to use as advice in creating policies because they base ethical arguments on generally recognised rational grounds (Ten Have 2013a:22; Ten Have \& Gordijn 2014:837).
The above arguments lead to the conclusion that there are strong arguments in favour of a link between human rights and global bioethics. The article now turns to the main argument against a link between human rights and global bioethics as the UNESCO literature indicates it.

\section{Arguments against a link between a global bioethics and human rights}

In this section objections against a link between bioethics and human rights are discussed and evaluated. Firstly, it is indicated that the objections centre on the issue of a foundation for human rights; and secondly, it is shown that it is agreed that the emphasis has shifted to the principles away from the foundation of the principles.

\section{Differences regarding the foundation}

In the bioethical community there are several objections to linking human rights and bioethics as found in the UNESCO declaration (Semplici 2015:58). In this regard Ten Have and Gordijn (2014:837-839) refer to the following bioethicists (mainly from outside the UNESCO environment): J.S. Gordon, D. Schroeder, D. Benatar, R.E. Ashcroft and H. Sakamoto. Ten Have and Gordijn discuss the objections, but they also indicate two related arguments that make out the strongest case against the link. The first objection focuses on the absence of consensus on the foundation (justification or origin) of human rights (and global bioethics) and the second, which flows from the first objection, is that universality is not possible (Tham 2011:9).

One of the contemporary arguments against the use of human rights, and therefore also against the link between universal bioethics and human rights, is that there is no communis opinio among academics, religious parties and the secular world with regard to the justification (foundation) of human rights, which means that the universality of human rights is questioned. Since unanimity on the foundation of human rights is lacking, using these principles is impossible. Stott (2011:197) states his opinion, saying: 'There is a need for some moral framework beyond human rights from which they can derive their authority and which provides their foundation'. In the past there was simply a call on God as the source of human dignity and human rights, but in a secular world this is not possible (Faunce 2014:468-468; Ten Have \& Gordijn 2014:838).

The question is whether this argument is strong enough to render the use of human rights invalid. Even if people differ on the foundation of human rights, the realities of human life show that people with different persuasions can formulate bioethical principles together because from a theological point of view they have an innately created gift to formulate ethical truth, as will be shown later on.

\section{Agreement on principles}

Semplici (2015) has the following opinion about the agreement on principles: 
Under the pressure of these criticisms, one could even be tempted to say that the time has come to abandon the human rights approach and be satisfied with registering the plurality of philosophies, and harmonizing them as much as possible. I think there are ... sound reasons not to do that. (p. 58)

Semplici puts forward two arguments to counter the above rejection of the link between bioethics and human rights. The first, a pragmatic argument, is supported by the second argument, which is theological in nature. These two arguments should be seen in the light of the very important remark by Donnelly (2012:19) on human rights and natural law: 'None, however, can through logic alone compel the agreement of a sceptic. Beyond the inevitable internal or "epistemological" challenges, foundational arguments are vulnerable to external or "ontological" critique'.

The two arguments are introduced by the well-known statement of Jacques Maritain: 'We agree about the rights but on condition no one asks us why' (UNESCO 1948:1). The first argument focuses on the fact that people agree. People from diverse backgrounds in the practice of this broken reality do indeed agree on the fact and content of human rights. It is indicated that the human rights debate started moving away from the emphasis on the underlying theory round about 1970 to focus mainly on the principles with which all people could agree (Ten Have 2013a:21-22). This means that the focus has been shifted to consensus about specific rights and ethical principles, irrespective of the origin or theoretical foundation of the principles. The (modern) human rights discourse has brought a distinction between theory and practice and has succeeded in keeping the underlying justification and the actual principle separated (Tham 2011:9). The same goes for the bioethical discourse where the emphasis is on 'common morality', which indicates values that are accepted by all people, irrespective of religion or philosophical persuasion (Beauchamp \& Childress 2013:2-4). A practical example is that the right to health can be enforced by courts and pressure groups without the fact that there are fundamental philosophical or theological consensus on the theoretical foundation of the concept of health. Human rights have made it possible to disentangle the bioethical discourse from the debate on the theoretical foundation as condition for accepting certain principles. Ten Have (2013a) puts it as follows:

By freeing the discourse from its underlying philosophical and theological justifications and from the controversies around these, human rights discourse became a public discourse, just like the bioethics discourse after it was disconnected from the medical profession that traditionally dominated medical ethics. (p. 170)

The focus on practical consensus as regarding principles instead of emphasising theoretical grounds in all probability resulted in the UDBHR being unanimously accepted by all the member countries of UNESCO in 2005. The reason for the shift in focus away from the theoretical grounding of human rights is explained as follows by Ten Have and Gordijn (2014:841):
One cannot argue that practical action is impossible as long as there is no comprehensive consensus on foundations and all the pivotal concepts. In numerous countries, there are important ethical issues 'on the ground' that require decisions in conditions of uncertainty.

The statement of Jacques Maritain in the second place does stimulate one to ask the following question and to offer a preliminary answer: Why can people of different faiths and philosophical persuasions develop bioethical principles like those in the UNESCO instrument together and reach consensus? The answer leads to a suggestion for a foundation for a global bioethics.

\section{Natural law as foundation for a global bioethics}

The reason why all people, regardless of faith or philosophical persuasion, could develop the bioethical principles contained in the UDBHR is that all people have the inherent capacity to develop ethical principles together. With regard to the question why unanimous consensus as found in the UDBHR of UNESCO has become a reality. Vorster (2015) suggests the following answer from a reformed perspective:

How else can one explain the existence of universal human rights? ... In addition one can ask how concepts such as general morality, universal ethical norms and 'the common good' can be understood if it is not taken back to the reality of natural law, which is founded on the creational revelation? (p. 55)

It is remarkable to note that the UNESCO commentator Faunce (2014:469) does not shy away from offering natural law as a foundation for the UDBHR when he comments as follows in Handbook of Global Bioethics: 'Rather, bioethics and human rights may be emergent expressions of a unique human contribution to the perception and heightening of order in the universe - conscience'.

This theological contribution claims that it is possible for all people 'without distinction of race, religion, political belief, economic or social condition' (in the words of Article 14 of UDBHR 2006) to formulate an ethos in the form of global bioethics and human rights (VanDrunen 2012:loc 80). It is indeed possible to share values despite different theoretical points of departure; in this sense the argument of lacking theoretical consensus is not valid. I agree with the preliminary answers provided by Faunce, Vorster and VanDrunen who offer a concise Christian argument for the existence of human rights and a global bioethics. The existence of and link between universal human rights and a global bioethics can be founded on the theological doctrine of natural law. It has to be noted that more and more bioethicists are using natural law to consider ethical norms in bioethics (Taylor 2010:405).

According to VanDrunen (2009:33) God's relationship with the world forms the backdrop to an understanding of natural law. The Bible reveals the development of a universal legal system with the aim of ruling a diverse and broken human existence after the fall of man. König (2010:113-114) indicates 
that Genesis 1-11 deals with universal human history and that it should be understood as follows: firstly, God is universally involved from the beginning (or in a covenant with all of humanity or all living beings, Gn 9:16); secondly, the part deals with matters that humanity has in common (Kelly, Magill \& Ten Have 2013:15; Vorster 2004:42). The manner of the involvement and communality which König does not mention explicitly, is made clear by VanDrunen (2009):

Genesis 4:15 and 9:6 are particularly relevant. In both of these texts, God ordained a system of human justice not as the sole possession of those who believed in him but as the common possession of the human race. (pp. 31-33)

In this sense the world's people are brothers and sisters of one another (Am 1:9) with the common goal of promoting a universal system of peace and stability in a diverse world (Jr 29:4-7). This system of universal human justice springs from natural law.

What is understood by natural law (lex naturae)? In addition to the above arguments, one presupposition is that God reveals his will in three ways, namely in the Bible, through Christ and in nature (God's works in creation). The details of Article 2 of the Belgic Confession, together with John 1:1 and 14 , serve as foundation for this point of departure. The sources in all three methods of revelation provide the human race with knowledge and a foundation for ethical behaviour. Natural revelation also means natural law. The term refers to moral knowledge acquired from the world (notitia acquisita) and human nature (notitia insita). It is independent of any supernatural revelation, it can be uncovered by reason and conscience and acquiring it is part of the duty of humanity (Moltmann 1985:57; VanDrunen 2012:loc 80;). In short natural law implies that God's revelation in conscience, reason, tradition, history, natural sciences and the insights from other worldviews can play a role in the identification and formulation of (Christian) ethical principles.

The foundation of natural law as theological point of departure is found in the fact that humans were created in the image of God. God is a good and holy moral being (Is 6:5). Justice forms part of the being of God as King. God loves the law and establishes that which is right (Ps 99:4). The good, holy King created all human beings in his image, which means that there is an agreement between God and the human being (Gn 1:26; Job. 31:13-15). The human being does not have the image of God, but is the image of God (1 Cor 11:7). Waldron (2010:227-228) also links the practical reason with the image of God. The human being was created as a moral being that, like God, inherently knows what is right; he or she was also given a mandate to establish what is right (Eph 4:24). Knowledge, including moral knowledge, forms part of the creation of the human being as the image of God (Col 3:10; VanDrunen 2012:loc 205-242). The Bible indicates that the fall into $\sin (\mathrm{Gn} 3)$ did not destroy the theological foundation of natural law, since there is a clear indication that the human being did not lose his status as the image of God (Gn 9:6; Ja 3:9). The implication of being the image of God is that natural law is part of the created human being. Moral logic forms part of human nature and life (Tham 2011:11).
Furthermore the Old Testament Scripture provides proof of how natural law establishes a sense of morality among people. Genesis 20 indicates that the unbelieving Abimelech acted morally just in his judgement of Abraham's lie. The New Testament indicates that God is the Creator of all people (Rm 1:25) and that natural law as a sense of morality is part of the creational acts of God. A sense of justice is part of the sinful human being from conception. Romans 2:14-15 testifies that in unbelievers 'the requirements of the law are written in their hearts'. Natural law is present in all people, whether they are believers or non-believers (Vorster 2015:57-58). Paul equates the demands of the heart to the Ten Commandments which implies that God is the origin of natural law, a truth that is repeated in Romans 1:32 (VanDrunen 2012:loc 299-313). Natural law as point of departure is Christologically supported. In Matthew 7:12 Jesus uses the well-known Golden Rule that is shared by most religions and philosophical traditions. The origin of this shared truth is natural law. In using this rule, Jesus wants to highlight the reality that common ethical truth does exist outside Christianity and that shared values are indeed possible and should be pursued (Østnor et al. 1995:19). However, if uncertainty exists about principles that flow from natural law, the principles should be tested by the written Word and the love of Christ as final judgement (Vorster 2015:80).

In the light of the above point of departure of natural law it is possible to find moral principles also in the form of human rights, that are valid for all people (Vorster 2015:58). For this reason one can accept that a non-religious organisation such as UNESCO can formulate good bioethical principles that link with human rights. This moral sense protects society and the world from total chaos and anarchy and promotes peace.

\section{Conclusion}

The UNESCO declaration is especially aimed at Africa and other developing countries. The acceptance of this UNESCO instrument shows that global bioethics and human rights have become part of the bioethics discourse of today. It is clear that a certain affinity between human rights and bioethics makes such a link desirable. The value of such a link lies in the fact that human rights enable a normative universal expansion of bioethical principles and that the human rights framework provides bioethical principles with authority and political influence, an instrument that can protect people in a broken context. Human rights practice and the reformed understanding of natural law show that humanity can reach consensus on ethical principles as found in the UDBHR and that consensus on the theoretical foundation of human rights is not a prerequisite for using these principles.

\section{Acknowledgements Competing interests}

The author declares that he has no financial or personal relationships which may have inappropriately influenced him in writing this article. 


\section{References}

Andorno, R., 2009, 'Article 3: Human dignity and human rights', in H. Ten Have \& M. Jean (eds.), The UNESCO Universal declaration on bioethics and human rights: Background, principles and application, Ethics series, pp. 91-98, UNESCO, Paris.

Beauchamp, T.L. \& Childress, J.F., 2013, Principles of biomedical ethics, 7th edn., Oxford University Press, New York.

Berlinguer, G., 2009, 'Article 23: Bioethics education, training and information', in $\mathrm{H}$. Ten Have \& M. Jean (eds.), The UNESCO universal declaration on bioethics and human rights: Background, principles and application, Ethics series, pp. 303-308, UNESCO, Paris.

Council for International Organizations of Medical Sciences (CIOMS), 2002, International ethical guidelines for biomedical research involving human subjects CIOMS, Geneva, viewed 25 May 2016, from http://www.recerca.uab.es/ceeah/

Council of Europe Convention on Human Rights and Biomedicine, 1997, Convention for the protection of human rights and dignity of the human being with regard to the application of Biology and Medicine, Oviedo, 1997, viewed 24 May 2016, from http://www.vib.be/VIBDocumentLibrary/EN/Convention_on_Human_Rights
and_Biomedicine.pdf

Donnelly, J., 2012, Universal human rights in theory and practice, 3rd edn., Cornell University Press, Ithaca, NY.

Faunce, T.A., 2014, 'Bioethics and human rights', in H.A.M.J. Ten Have \& B. Gordijn (eds.), Handbook of global bioethics, pp. 467-484, Springer Science, Business Media, Dordrecht.

Iltis, A.S., 2011, 'Global bioethics and natural law', in C. Tollefsen (ed.), Bioethics with liberty and justice: Themes in the work of Joseph M. Boyle, pp. 145-162, Springe Science, Business Media, Dordrecht.

International Bioethics Committee (IBS) of UNESCO, 2004, 'Eleventh session International Bioethics Committee of UNESCO', viewed 18 November 2013, from
http://portal.unesco.org/shs/en/files/7495/11103874181ReportCIB11_en.pdf/ http://portal.unesco.
ReportClB11 en.pdf

International Bioethics Committee (IBC) of UNESCO, 2008, 'Report ... on Consent', viewed 25 May 2016, from http://unesdoc.unesco.org/images/0017/001781/ 178124e.pdf

Kelly, D.F., Magill, G. \& Ten Have, H., 2013, Contemporary Catholic health care ethics, 2nd edn., Georgetown University Press, Washington, DC.

Kirby, M., 2006, 'UNESCO and universal principles in bioethics: What's next?', in International Bioethics Committee of UNESCO (IBC), Twelfth session, Tokyo, Japan, 15-17 December 2005, Proceedings, pp. 121-136, UNESCO, Division of Ethics of Science and Technology Social and Human Science Sector, s.l., viewed 25
2016, from http://unesdoc.unesco.org/images/0014/001484/148404e.pdf

König, A., 2010, Alle paaie lei na Jesus, CUM Books, Vereeniging.

Langlois, A., 2013, Negotiating bioethics: The governance of UNESCO's bioethics programme, Routledge, Abingdon.

Macaleer, R.D., 2014, The New Testament and bioethics: Theology and basic bioethics principles, Pickwick Publications, Eugene, OR.

Mathooko, J.M. \& Kipkemboi, J.K., 2014, 'African perspectives', in H.A.M.J. Ten Have \& B. Gordijn (eds.), Handbook of global bioethics, pp. 253-268, Springer Science, Business Media, Dordrecht.

Moltmann, J. 1985, God in creation: An ecological doctrine of creation, Gifford lectures 1984-1985, SCM, London.

Nuremberg Code, 1947, viewed 25 May 2016, from https://history.nih.gov/research/ downloads/nuremberg.pdf; https://www.ushmm.org/information/exhibitions/ online-features/special-focus/doctors-trial/nuremberg-code\#Permissible

Office of the United Nations High Commissioner for Human Rights (OHCHR), 1996-2016, What are human rights?, viewed 20 May 2016, from http://www. ohchr.org/EN/Issues/Pages/WhatareHumanRights.aspx

Østnor, L., Hallamaa, J., Andersen, S., Björnssom, B., Nilsson, G. \& Thunberg, L., 1995 'The Lutheran approach to bioethics', in V. Mortensen (ed.), Life and death: Moral implications of biotechnology, pp. 9-34, WCC Publications, Geneva, IL.

Semplici, S., 2015, 'The imperative of sharing', in G. Solinís (ed.), Global bioethics: What for? Twentieth anniversary of UNESCO's Bioethics programme, UNESCO Paris, viewed 25 May 2016, from http://unesdoc.unesco.org/images/0023/ 002311/231159e.pdf
Stanton-Jean, M., Doucet, H. \& Le Roux, T., 2014, 'Informed consent', in H.A.M.J. Ten Have \& B. Gordijn (eds.), Handbook of global bioethics, pp. 737-754, Springer Have \& B. Gordijn (eds.), Handbook
Science, Business Media, Dordrecht.

Stott, J.R.W., 2011, Issues facing Christians today, Zondervan, Grand Rapids, MI.

Taylor, C., 2010, 'Challenging issues about the secular age', Modern Theology 3(404). http://dx.doi.org/10.1111/j.1468-0025.2010.01615.x

Ten Have, H., 2011, Bioethiek zonder grenzen: Mondialisering van gezondheid, ethiek en wetenschap, Valkhof Pers, Antwerpen.

Ten Have, H., 2013a., 'Bioethics and human rights: Wherever the twain shall meet', in S. Vöneky, B. Beylage-Haarmann, A. Höfelmeier \& A.K. Hübler (eds.), Ethik und Recht: Die Ethisierung des Rechts = Ethics and law: The ethicalization of law, Recht: Die Ethisierung des Rech
pp. 149-176, Springer, Berlin.

Ten Have, H., 2013b, 'Global bioethics: Transnational experiences and Islamic bioethics', Zygon 48(3), 600-617. http://dx.doi.org/10.1111/zygo.12035

Ten Have, H. \& Gordijn, B., 2014, 'Future perspectives', in H.A.M.J. Ten Have \& B. Gordijn (eds.), Handbook of global bioethics, pp. 829-844, Springer Science, Business Media, Dordrecht.

Tham, J., 2011, 'Natural law and global bioethics', Studia Bioethica 4, 7-16.

Tham, J., 2014, 'Introduction: The principle of vulnerability: Meeting ground of six religions', in J. Tham, A. Garcia \& G. Miranda (eds.), Religious perspectives on human vulnerability in bioethics, pp. 1-7, Springer, Dordrecht.

UDBHR, see UNESCO

UNESCO, 1948, Human rights: Comments and interpretations: A symposium edited by UNESCO, with an introduction by Jacques Maritain, UNESCO, Paris, viewed 27 May 2016, from http://unesdoc.unesco.org/images/0015/001550/155042eb.pdf

UNESCO, 1987, 'Records of the General Conference, 24th session, Paris, 20 October to 20 November, vol. 1, Resolutions', pp. 105-117, viewed 26 May 2016, from http:// unesdoc.unesco.org/images/0007/000769/076995E.pdf

UNESCO, 1997, Universal declaration on the human genome and human rights, viewed 24 May 2016, from http://portal.unesco.org/en/ev.php-URL_ID=13177\& URL_DO=DO_TOPIC\&URL_SECTION $=201 . \mathrm{htm}$

UNESCO, 2003, International declaration on human genetic data, viewed 24 May 2016, from http://portal.unesco.org/en/ev.php-URL_ID=17720\&URL_DO=DO_ TOPIC\&URL_SECTION=201.html

UNESCO, 2005, 'Records of the General Conference, 33rd session, Paris, 3-21 October 2005, vol. 1, Resolutions', viewed 26 May 2016, from http://unesdoc.unesco.org/ images/0014/001428/142825e.pdf

UNESCO, 2006, Universal declaration on bioethics and human rights, adopted by acclamation on 19 October 2005 by the 33rd session of the General Conference of UNESCO, viewed 17 April 2016, from http://unesdoc.unesco.org/images/0014/ 001461/146180E.pdf

United Nations (UN), 1949, Universal declaration of human rights 1948, viewed 24 May 2016, from http://www.jus.uio.no/Im/un.universal.declaration.of.human. rights.1948/portrait.a4.pdf

VanDrunen, D., 2009, Bioethics and the Christian life: A guide to making difficult decisions, Crossway, Wheaton, IL.

VanDrunen, D., 2012, A biblical case for natural law, Kindle edition, Christian social thought series, Acton Institute, Grand Rapids, MI.

Vorster, J.M., 2004, Ethical perspectives on human rights, Potchefstroom Theological Publications, Potchefstroom.

Vorster, J.M., 2015, Christelike etiek in 'n sekulariserende samelewing, AOSIS, Durbanville.

Waldron, J., 2010, 'The image of God: Rights, reason, and order', in J. Witte \& F.S. Alexander (eds.), Christianity and human rights: An introduction, Cambridge University Press, Cambridge.

World Medical Association (WMA), 2013, 'World Medical Association Declaration of Helsinki: Ethical principles for medical research involving human subjects', adopted by the 18th WMA General Assembly, Helsinki, Finland, June 1964, and amended by the 64th WMA General Assembly, Fortaleza, Brazil, October 2013, JAMA 310(20), 2191-2194. http://doi:10.1001/jama.2013.281053 